\title{
Tutoring Support in the Process of Mastering the Teaching Profession by Bachelor Students
}

\author{
Elena Kolosova ${ }^{1, a *}$, Elena Zhukova ${ }^{1, b}$ \\ 1 Moscow Pedagogical State University, 119991, 1/1 Malaya Pirogovskaya str., Moscow, Russia

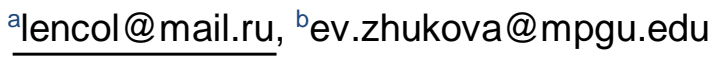 \\ ${ }^{*}$ Corresponding author
}

\begin{abstract}
Keywords: professional development, bachelor students, education, purpose of education, participants of educational relations, individual educational needs, educational navigation, methods of self-development
\end{abstract}

\begin{abstract}
Bachelor students of the specialty "Teacher of primary classes" study a lot of subjects in the fields of Pedagogy and Psychology. One such subject is "The methods of self-development". On that course students think about their purposes of education. The course involves research activities. Students get more information about themselves, get to know how communicate in different situations and check it out in practice at school. The paper focuses on the actual issues of tutoring support in the process of mastering the teaching profession by Bachelor students.
\end{abstract}

\section{Introduction}

A modern graduate of a pedagogical university appears in a rather complicated situation of "entering" into a profession. In addition to the traditional requirements for a high level of subject knowledge, understanding of the psychological characteristics of schoolchildren, an ability to build a dialogue with parents and teachers, a confident mastery of information technology, the primary school teacher is faced with the need to successfully integrate children of various categories into educational activities: pupils with disabilities, motivationally gifted students, children from migrant families who have a poor command of Russian and are carriers of another culture, children who are brought up in foster families, etc. Pedagogical work with these "special" children implies additional competences of the teacher, in particular, an understanding of the specifics of each of these categories, an ability to see oneself and disclose to the child educational perspectives and resources. So, the teacher himself needs to own a culture of self-education, that is, conscious building of an individual educational trajectory.

\section{Methods}

Analysis of scientific publications and results of applied research, qualitative analysis of the products of written work, as well as a survey (electronic questionnaire) and the method of statistical processing in Excel.

\section{Study}

Applied higher pedagogical education in Russia is traditionally focused on the deep development of subject and methodological areas, and the experience of the actual research line turns out to be excessive, not related to an individual educational request that does not affect the student's professional orientation.

In this regard, the process of preparing future teachers is optimally organized in such a way that the experience of academic research and search activity includes answers to the actual needs of students and is related to the pedagogical reality during the teaching practice (in real conditions of educational organizations). Consider the option of working with individual educational needs of students on the example of interaction with a teacher-tutor within the disciplines of the psychological-pedagogical module, which is implemented in different faculties of the Moscow State Pedagogical University from the 2015 academic year to the present. Together with a tutor, students consider the formulation of educational and professional meanings, goals, ways and strategies to achieve them, the analysis of planning tools, pedagogical self-support, and practices of self-education [9]. One of the cross-cutting issues of the course is to discuss a number of topics related to the professional portrait of a modern teacher. 
Students were asked to submit a "Professional Portrait of a Teacher", in which they formulated what characteristics in the teacher they payed attention first of all (Fig. 1).

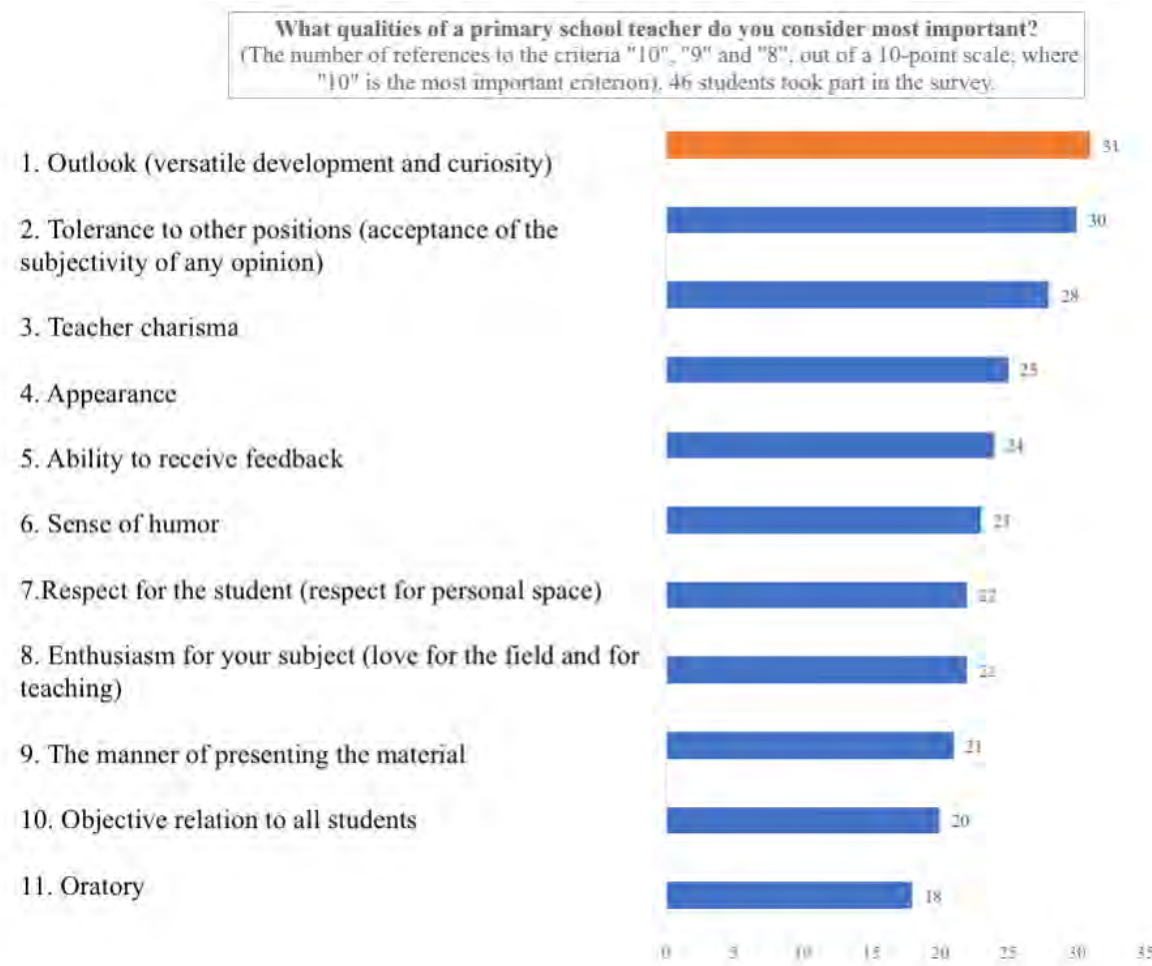

Fig. 1. The most significant qualities of a teacher, formulated by students in the process of tutoring support.

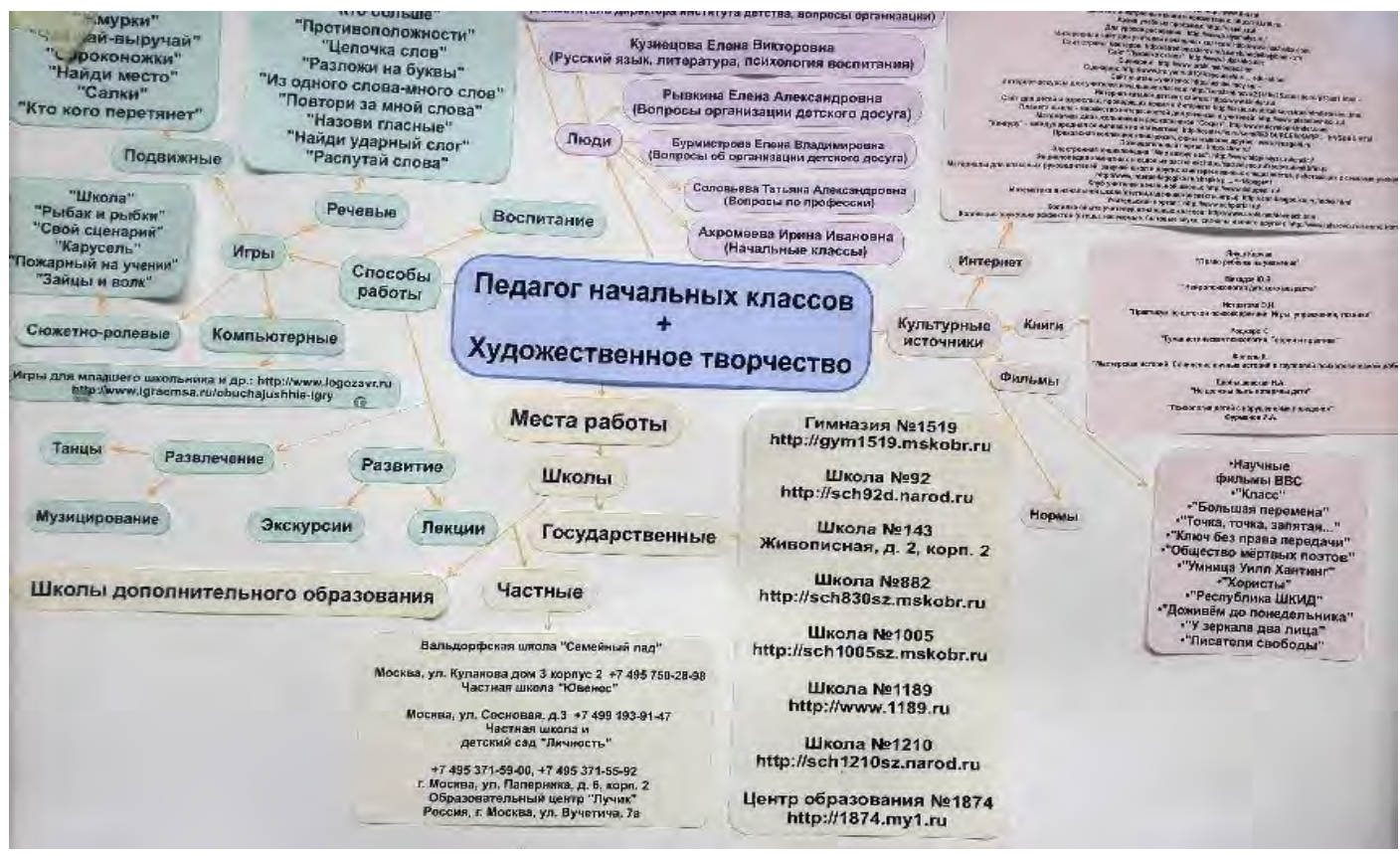

Fig. 2. Examples of "intellectual cards" of students on the topic of resources of the profession "Primary school teacher".

In the process of interaction with a tutor, the question is raised as to how declarative relations relate to each other (listed in regulatory documents, for example, in the Professional Standard "Teacher" $[5 ; 6]$ ), the competences of the teacher, and real, personal, and professional qualities to be implemented in practice. At the first stage, students turn to personal and group experience, formulate their own ideas about the resources of the teacher-practice. Figure 2 presents examples of the initial development of the teacher's "educational navigation": a list of people (professionals who they can turn to), places (where they can work or improve their skills), methods of work, and a "foundation" of basic literature. 
At this stage it was important to create a situation for students in which they would think about ways to achieve their educational intent. In the process of organized discussion by groups of students, the most important criteria for becoming them as professionals were selected, then the criteria were ranked by each of the students on the basis of his personal ideas (see Fig. 3).

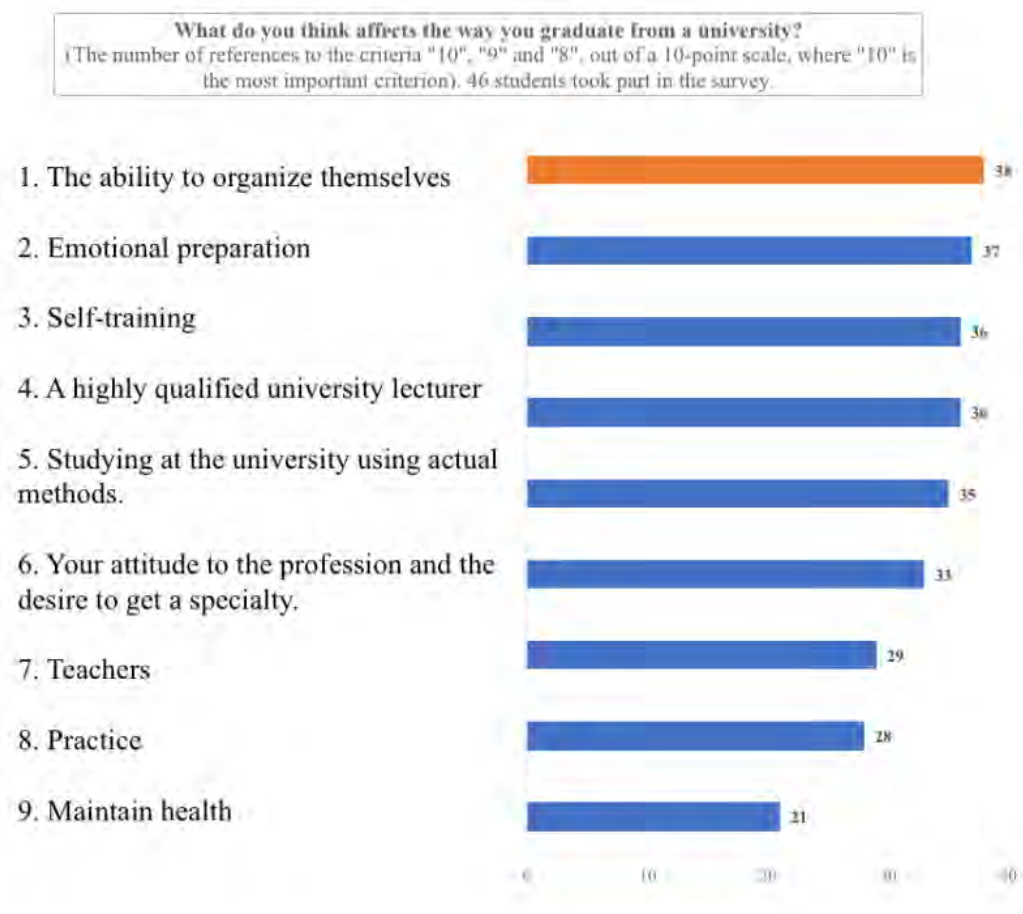

Fig. 3. The most significant criteria for the formation of a professional teacher, from the point of view of students of pedagogical bachelor degree, participants of tutor support.

Students compare primary measurements with the knowledge gained in the course of related disciplines of the psychological-pedagogical cycle (for example, psychological characteristics and the specificity of pedagogical approaches to an elementary school child).

Then, in educational institutions during the teaching practice, students collect information using specially designed surveys (questionnaires, tests, and interviews). Thus, each student has three blocks of materials: initial knowledge and judgments, additions and clarifications made from selected literary sources, results of surveys, and interaction with practicing teachers.

The next step is the formulation of a working hypothesis and its testing in practice. At the same time, the presence of the student's cognitive interest in the development of the selected problem, his motivation to continue the academic research is recorded. (With its pronounced absence, in our opinion, the result is correctly considered, conclusions are made by a student on a problem, and an informed decision about the logical conclusion of this work. The development of different types of activities is significant, along with a student's understanding of the internal logic of his individual educational path).

For example, in one of the groups, at the stage of communication with the pedagogical community, which for several years has been implementing inclusive educational practice, an obvious "deficit" realized by students has emerged: the lack of adequate modern formats of interaction with parents. We are talking not only about the families of children with special needs (the so-called group of disabled children, children with disabilities), but also about interaction with other parent groups, about conflict prevention, about ways of their adequate socially acceptable solution. It should be noted that this topic appeared quite unexpectedly for students and was not declared at the first stage, that is, it was not part of their student experience. The result of the analysis of the normative and legal corpus of texts brought us to the following conclusion: the interaction of educational organizations with families, namely: competent, pedagogically adjusted building of relations in the style of mutual respect, support and cooperation are the key areas identified in the new generation of the Federal State Educational Standard. According to the Law on Education in the Russian Federation [4], parents, as well as their substitutes, are legitimately recognized as "participants in 
educational relations". This legislative norm is increasingly having a real impact on the educational process. So, for example, one of the blocks of content of educational programs is built up based on the formed educational request - the social order. It is about that part of the curriculum which is formed by the participants of educational relations. Students concluded that the quality of the educational environment, the traditions adopted in an educational organization, the types and styles of communication are not currently formed out of touch with the parent community. The students noted that taking into account the views of parents on choosing forms of education, its content, the pedagogical technologies used in education apply to any child and are not specific to the organization of inclusive practices. However, if real active interaction with the parents of a normatively developing child in the situation of implementing the Federal State Educational Standard is extremely desirable, then in the case of teaching a child with a disability (and / or disability) it is necessary. This is connected with the development of a special, so-called adapted educational program, and with its implementation, which require real involvement of parents.

According to the surveys of teachers, conclusions were drawn that the well-known traditional formats of interaction between the school and parents do not meet modern needs, and the practice of using a virtual environment - network communities, an e-journal, a school website - needs to be supplemented by "live full-time" support. Thus, out of 140 pedagogical workers surveyed by students and representatives of the administration of educational organizations, more than half of them considers that regular interaction of teachers with parents "influences" school life. $62 \%$ of respondents assess this "influence" as constructive, potentially positive. $20 \%$ of them find it difficult to answer unambiguously. They express fears and see in this influence a potential "threat" (12\%). The following wishes were formulated to the quality and way of organizing interaction:

- Regularity, predictable schedule, openness and clarity of rules and restrictions;

- Rejection of teachers' positions as a "specialist providing educational services" and the adoption of the position of partnership as a shared responsibility.

After analyzing the nature of the request, comparing it with a number of legal justifications that relate to the communication of all "participants in educational relations," the students developed several options for interaction with the parent community.

In the pedagogical analysis of educational work following the results of each school year, school psychologists, social pedagogues, and the administration recorded an increase in the number of joint inclusive activities, including those being initiated by the parent community. Teachers also noted a decrease in oral complaints of parents about conflict situations related to the issues of inclusion. It goes without saying that the linear causal relationship of a number of measures and the nature of the positive dynamics in the changing educational environment do not seem to be correct, since this process is multidimensional and complexly organized. At the same time, the questionnaires of the parent and pedagogical community collected by students indicate the constructive significance of the interaction organized by them: $82 \%$ of respondents consider it necessary and reasonable to continue meetings. They speak about confidence in the improvement of comfortable co-education and upbringing of children (47\%), explaining these reasons, first of all, in-person meetings and awareness with the subject matter. (This effect can be noted: the personal perception of families with "special" children has noticeably increased. If at the beginning of the school year about $40 \%$ of reviews were of a generalized addressless nature ("sick children", "they", "these parents"), then similar forms in the reviews were used two times less, new stable combinations appeared, such as "we," "our children". In addition, the use of proper names became more frequent).

\section{Conclusion}

The inclusion of elements of educational research in the framework of tutor support of students in the process of passing their teaching practice seems to us quite effective. The discussion of individual ideas about professional activity with the prospect of entering an academic research that meets the actual, personally meaningful, educational request of a student is seen by us as one of the didactic tools or educational resources comparable to the "motivational dialogue," which E. Yu. Patyaeva extensively writes about [10]. "The core of self-determination (...) is the motivational dialogue - with other people or with oneself. The initial form of the motivational dialogue is an external dialogue with real interlocutors, which 
forms the motivational basis of a jointly defined action, which is different from both the specified action and the action of self-determination. This internal motivational dialogue is the fundamental psychological basis of human self-determination" [10, p.791]. Thus, the analysis of the phenomena of pedagogical reality based on the culture of research allows students to clarify ideas about their profession, to perceive the process of their own education as a more focused and consciously choose further areas of educational research that determine the logic of folding the educational route.

\section{References}

[1] Demakova, I. D. (2014). Domestic and foreign pedagogy, 5(20), Retrieved from https://cyberleninka.ru/article/n/vospitatelnaya-deyatelnost-pedagoga-v-usloviyah-paradigmalnogosdviga-metodologicheskiy-aspekt.

[2] Dovbysh, S. E., Kolosova, E. B, \& Arinushkina, A. A. (2018). Man and Education, 2(55), pp. 232-239.

[3] Dudchik, S. V. (2016). Business. Education. Right. Bulletin of the Volgograd Institute of Business, l(34), pp. 149-154.

[4] Ministry of Education and Science of Russia. (n.d.). The Law on Education (No. 273). Retrieved from https://www.minobrnauki.rf/documents/2974.

[5] Ministry of Education and Science of Russia. (2015). The Professional standard "Teacher." Retrieved from https://www.minobrnauki.rf/documents/3071/file/1734/12.02.15-Professtandard_pedagog (draft) .pdf)

[6] The Garant Database. (2016). The Professional standard "Specialist in the field of education." Retrieved from http://www.garant.ru/products/ipo/prime/doc/56570338/.

[7] Obukhov, A. S. (2014). Science and School, 5, pp. 138-144. Retrieved from https://cyberleninka.ru/article/n/professionalnaya-podgotovka-pedagoga-v-logike-subektnodeyatelnostnogo-podhoda.

[8] Obukhov, A. S., \& Zhukova, E. V. (2017). Problems of Modern Education, 5, pp. 78-85.

[9] Ognev, A. S., Dovbysh, S. E., \& Kolosova, E. B. (2018). Navigation: life, educational, professional: teaching aid. Moscow, Russia: MPGU.

[10] Patyaeva, E. Yu. (2018). Spawning action: cultural activity approach to human motivation. Moscow, Russia: Smysl.

[11] Aglen, B. (2016). Pedagogical strategies to teach bachelor students evidence-based practice: A systematic review. Nurse Education Today, 36, pp. 255-63.

[12] Thiele, L., Sauer, N. C., Atzmueller, M., \& Kauffeld, S. (2018). The co-evolution of career aspirations and peer relationships in psychology bachelor students: A longitudinal social network study. Retrieved from http://psycnet.apa.org/record/2018-14554-006.

[13] Raes, A. et al. (2018). Teaching for versus through Problem Solving: Impact on Teaching and Learning. - International Society of the Learning Sciences. (Presented at the International Conference of the Learning Sciences - ICLS)

[14] Ihme, A. \& Stürmer, S. (2018). Emphasizing excellence and diversity cues on university websites. Additive or interactive effects on prospective students' psychological reactions? Journal of Applied Social Psychology, 48, pp. 59-70. doi: 10.1111/jasp.12490 